\title{
A randomised pilot study to assess the efficacy of an interactive, multimedia tool of cognitive stimulation in Alzheimer's disease
}

\author{
L Tárraga, M Boada, G Modinos, A Espinosa, S Diego, A Morera, M Guitart, J Balcells, \\ O L López, J T Becker
}

See end of article for authors' affiliations

Correspondence to: L Tárraga, Fundació ACE, Institut Català de

Neurociències Aplicades Marquès de Sentmenat,

35-37, 08014 Barcelona, Spain;

Itarraga@fundacioace.

com

Received 9 December 2005 Revised version received 15 June 2006

Accepted 20 June 2006

Published Online First

4 July 2006
Objective: To determine the usefulness of an interactive multimedia internet-based system (IMIS) for the cognitive stimulation of Alzheimer's disease.

Methods: This is a 24-week, single-blind, randomised pilot study conducted on 46 mildly impaired patients suspected of having Alzheimer's disease receiving stable treatment with cholinesterase inhibitors (ChEls). The patients were divided into three groups: (1) those who received 3 weekly, 20-min sessions of IMIS in addition to $8 \mathrm{~h}$ /day of an integrated psychostimulation program (IPP); (2) those who received only IPP sessions; and (3) those who received only ChEl treatment. The primary outcome measure was the Alzheimer's Disease Assessment Scale-Cognitive (ADAS-Cog). Secondary outcome measures were: MiniMental State Examination (MMSE), Syndrom Kurztest, Boston Naming Test, Verbal Fluency, and the Rivermead Behavioral Memory Test story recall subtest.

Results: After 12 weeks, the patients treated with both IMIS and IPP had improved outcome scores on the ADAS-Cog and MMSE, which was maintained through 24 weeks of follow-up. The patients treated with IPP alone had better outcome than those treated with ChEls alone, but the effects were attenuated after 24 weeks. All patients had improved scores in all of the IMIS individual tasks, attaining higher levels of difficulty in all cases.

Conclusion: Although both the IPP and IMIS improved cognition in patients with Alzheimer's disease, the IMIS program provided an improvement above and beyond that seen with IPP alone, which lasted for 24 weeks.
A lzheimer's disease is the most frequent form of dementia in elderly people, ${ }^{12}$ and its current treatment includes cholinesterase inhibitors (ChEIs), ${ }^{3-5}$ and $\mathrm{N}^{-}$ methyl-D-aspartate receptor blockers (eg, memantine). ${ }^{6}$ However, symptomatic treatment often entails non-pharmacological treatments as well, and adequate dementia management requires a wide range of intervention to help maximise the patient's independence, increase their self-confidence and relieve burden to the care giver.

Current symptomatic treatment of Alzheimer's disease can improve cognition and functionality. ${ }^{3-6}$ However, before the emergence of these drugs, non-pharmacological treatments had already been evaluated and cognitive stimulation had been found to be potentially beneficial for patients with dementia. ${ }^{7-9}$ Although these non-pharmacological treatments do not always seem efficacious, methodological problems may limit the validity of some studies. ${ }^{10}$ A recent Cochrane revie $w^{11}$ emphasised caution when interpreting the results of non-pharmacological treatments, but suggested that certain cognitive domains could, in fact, benefit from these types of interventions.

Clinical and laboratory studies have shown that mental and physical activity can positively influence cognition in normal elderly people and people with dementia. Education ${ }^{12}$ and lifestyle choices (eg, occupation and leisure activities) $)^{13-15}$ can modulate the risk of developing dementia, and psychomotor stimulation improves cognition in patients with Alzheimer's disease. ${ }^{16}{ }^{17}$ Environmental enrichment can improve cognition in transgenic mice. ${ }^{18} 19$ Despite the continued deposition of $\beta$-amyloid, exercise can increase the levels of brain-derived neurotrophic factor ${ }^{20}$ and may reduce amyloid burden. ${ }^{21}$
Despite the progressive nature of the degenerative process, patients with Alzheimer's disease also seem to retain the physiological capacity to alter brain structure and function. Recent studies have shown cognitive plasticity and learning potential not only in patients with Alzheimer's disease but also in healthy elders. ${ }^{22}{ }^{23}$ Positron emission tomography studies that used activation paradigms ${ }^{24}{ }^{25}$ have found that people with Alzheimer's disease have a greater activation than those without dementia in the brain regions usually associated with memory tasks, as well as in the frontal lobes that were activated only with increasing difficulty of tasks. Pathological studies conducted on biopsy specimens of patients with Alzheimer's disease with mild or moderate dementia have shown increased synaptic contact size. ${ }^{26}$ Thus, the brain may be able to compensate during the early stages of Alzheimer's disease, suggesting that there may be some utility to non-pharmacological adjunctive interventions.

Although studies on cognitive stimulation show that it is possible to stimulate the memory of patients with Alzheimer's disease, the results are often modest. Because of methodological limitations, there is a need to conduct more randomisedcontrolled trials with larger samples to validate this therapeutic approach. Computerised systems ${ }^{27}$ and internet-based distance programs offer one potential mechanism by which nonpharmacological cognitive stimulation can be conducted in

Abbreviations: ADAS-Cog, Alzheimer's Disease Assessment ScaleCognitive; BNT, Boston Naming Test; ChEls, cholinesterase inhibitors; GDS, Global Deterioration Scale; IMIS, interactive multimedia internetbased system; IPP, integrated psychostimulation program; MMSE, MiniMental State Examination; RBMT, Rivermead Behavioral Memory Test; SKT, Syndrom Kurztest 
patients with dementia. In this study, we evaluated an interactive multimedia internet-based system (IMIS) as an adjunct to ChEI treatment and classic psychostimulation treatment.

\section{MATERIALS AND METHODS}

Forty six patients suspected of having Alzheimer's disease ${ }^{28}$ were recruited for the study through a referral clinic and daycare centre (Fundació ACE, Institut Català de Neurociències Aplicades, Barcelona, Spain). The Institut Català de Neurociències Aplicades is a referral diagnostic clinic for community-dwelling people with dementia, and also provides adult daycare services to these patients. All of the patients had been treated with ChEIs for at least 1 year before inclusion to the study. The inclusion criteria were:

- $>65$ years of age;

- at least 3 years of education;

- a Mini-Mental State Examination (MMSE) ${ }^{29} 30$ score between 18 and 24;

- a Global Deterioration Scale (GDS) ${ }^{31}$ score of 3 or 4;

- absence of uncontrolled disruptive behaviours (eg, aggression, delusions, hallucinations and agitation) that could interfere with program administration and/or neuropsychological assessments;

- absence of major depression, current or partial remission ${ }^{32}$;

- absence of structural lesions in the computed tomogram or magnetic resonance image;

- absence of history of alcohol or other substance abuse; and

- absence of severe auditory, visual or motor deficits that may interfere with cognitive testing.

None of the participants had previous experience with a personal computer and all attended the daycare centre 5 days/week. Participants were allowed to be on stable doses of psychotropic drugs.

\section{Multimedia treatment}

The IMIS was conducted using Smartbrain (http://www. educamigos.com), an interactive multimedia tool that allows patients to carry out a variety of different stimulation programs, at different levels of difficulty and at various times during the day. Briefly, the IMIS program consists of 19 separate "tasks" or stimulation exercises across the domains of attention, calculation, gnosis, language, memory and orientation. All participants began at the lowest level of difficulty (first of 15 levels) and the program monitored activity at each level. Difficulty increased automatically after three consecutive performances within a single task without error, or when a patient was $80 \%$ correct over six consecutive sessions. A patient's level of difficulty decreased when his or her performance fell below 15\% correct for three consecutive sessions or $<20 \%$ correct for six consecutive sessions. All patients were trained before the study with the use of the computer mouse, especially on how to "click and drag".

\section{Integrated psychostimulation program}

The IPP is a daily program in the daycare centre that includes cognitive stimulation tasks, workshops (eg, music therapy, art and crafts, and physical activity) and reinforcement of instrumental activities of daily living. ${ }^{17}$ The IPP is integrated into the daycare centre activities, and it takes $2 \mathrm{~h}$ in the morning and $1.5 \mathrm{~h}$ in the afternoon out of the $8 \mathrm{~h}$ that the patients spend in the centre.

Each patient was randomly assigned to one of three study groups:
- Experimental group: These patients received the IMIS, as well as the IPP and ChEIs.

- IPP control: These patients received IPP and ChEIs.

- ChEIs control: These patients received only ChEIs.

The ChEIs group comprised of patients who were diagnosed with Alzheimer's disease, but who were living at home, and never received the IPP or the IMIS. These patients either did not want to come to the daycare centre, although they agree to be followed clinically, or were on a waiting list for admission to the daycare centre. The experimental and the IPP control groups were participants in the daycare centre, and the only difference between these two groups was that the experiment group received the IMIS. Written informed consent was obtained from all the participants enrolled in the study and their legal representative before the study onset.

Three patients in the experimental group dropped out of the study: one because of rapid progression of the disease and two because of institutionalisation. Consequently, from the initial sample of 46,43 patients completed the study: 15 in the experimental group, 16 in the IPP control group and 12 in the ChEI control group (table 1).

\section{Experimental group}

These patients received the IMIS, IPP and ChEIs.

\section{IPP control}

These patients received IPP and ChEIs.

\section{ChEl control}

These patients received only ChEIs.

No significant differences were observed between the groups in terms of age $\left(\mathrm{F}_{2,41}=0.72\right)$ or level of education $\left(\chi^{2}=5.513, \mathrm{df}=4, \mathrm{p}=0.239\right)$. There was a tendency for a difference in the proportion of male patients, primarily because all the patients in the ChEI group were female; however, the difference was not significant $\left(\chi^{2}=5.70, \mathrm{df}=2\right.$, $\mathrm{p}=0.06)$.

Patients were assessed at study entry, and after 12 and 24 weeks of treatment. The primary outcome measure was the Alzheimer's Disease Assessment Scale-Cognitive (ADASCog) section. ${ }^{33}$ This is a standardised measure of cognitive function that examines components of memory, language, visuoconstructional and ideational praxis, and orientation. High ADAS-Cog scores indicate worse performance. The secondary measures were:

- MMSE: This is a global measure of cognitive function that examines orientation to time and place, immediate and delayed recall of three words, attention and calculation, language and visuoconstructional functions.

- Syndrom Kurztest $(S K T)^{34}$ : This is a short cognitive performance test that examines memory and attentional functions.

- Boston Naming Test (BNT) $)^{35}$ : Patients must name 60 large ink drawings that are presented to them by the examiner.

Table 1 Demographic characteristics of the patients

\begin{tabular}{llll}
\hline & $\begin{array}{l}\text { Experimental } \\
\text { group }\end{array}$ & $\begin{array}{l}\text { IPP control } \\
\text { group }\end{array}$ & $\begin{array}{l}\text { ChEl control } \\
\text { group }\end{array}$ \\
\hline Patients & 15 & 16 & 12 \\
Male/female & $5 / 13$ & $2 / 14$ & $0 / 12$ \\
Mean age & $75.8(5.9)$ & $77.4(4.7)$ & $76.9(4.5)$ \\
(SD) & & &
\end{tabular}

(SD)

ChEl, cholinesterase inhibitor; IPP, integrated psychostimulation program. 
The test is discontinued after eight consecutive failures. When the patient fails to name the drawing, the examiner provides a semantic cue; if still unable to name the drawing, a phonemic cue is provided.

- Verbal fluency: This includes letter generation (letter P) and animal fluency tests.

- The story recall subtest from the Rivermead Behavioral Memory Test $(R B M T)^{36}$ : Patients listen to a short passage of a prose being read aloud and then recall as much as they can.

- Rapid Disability Rating Scale-2 (RDRS-2) $)^{37}$ : This is an assessment of three functional and behavioural areas: (a) help with activities of daily living, (b) degree of disability, and (c) degree of special problems (ie, mental confusion, uncooperativeness and depression). The RDRS-2 was administered at baseline and at 24-week follow-up examination.

- $G D S^{31}$ : This is a staging system of seven distinguishable cognitive and functional stages, ranging from normal (stage 0) to severe dementia (stage 7). All patients in the study had a GDS stage 4.

The primary and secondary outcome measures were administered to all participants in the experimental and IPP control groups at all visits. Owing to manpower limitations, the BNT, verbal fluency tests and RBMT (all secondary outcome measures) were not administered to the ChEI control group at any visit.

\section{INTERACTIVE MULTIMEDIA INTERVENTION}

Patients in the experimental group received a total of 72 IMIS sessions, three times a week for 24 weeks. All of the patients in the experimental group had the same computerised activities, order of presentation and session length. During the first 24 sessions, the IMIS sessions lasted only $15 \mathrm{~min}$. Sessions 25-28 lasted $20 \mathrm{~min}$, and sessions 29-72 lasted $25 \mathrm{~min}$. Because this was the first time that such a computerised multimedia program was applied for the cognitive stimulation of these patients, it was necessary to ensure tolerability and adequate dose to avoid fatigue or other possible negative effects that might arise from exposure to a PC. A minimum requirement was that the participants completed 58 of $72(80 \%)$ sessions, with an interruption of no more than 10 days between sessions; all participants met this criterion.

\section{STATISTICAL ANALYSIS}

The data were analysed using SPSS V.12. Descriptive statistics were prepared at baseline, 12 weeks and 24 weeks. Outcomes were assessed using one-way analysis of variance at each of the three critical time points.

\section{RESULTS}

Table 1 shows the characteristics of the groups.

No significant differences were observed between the three study groups on the ADAS-Cog $\left(\mathrm{F}_{2,42}=0.67\right)$ or SKT $\left(\mathrm{F}_{2,42}=0.84\right)$ at baseline, although the experimental group had slightly lower MMSE scores than the other groups $\left(F_{2,42}=3.33, p=0.046\right.$; table 2$)$. There were no differences between the experimental and the IPP control groups on the other neuropsychological measures at baseline examination (the ChEI control group did not receive these additional four tests; table 2).

After 12 weeks of treatment, the three study groups differed in terms of the ADAS-Cog $\left(\mathrm{F}_{2,42}=7.05, \mathrm{p}=0.002\right.$, $\mathrm{r}=0.50)$ and the MMSE $\left(\mathrm{F}_{2,42}=10.3, \mathrm{p}<0.001, \mathrm{r}=0.57\right.$; fig 1). Both experimental and IPP control groups were superior to the ChEI control group on the ADAS-Cog (Dlysergic acid diethylamide test, $\mathrm{p}<0.05$ ), and all three groups differed from each other on the MMSE (D-lysergic acid diethylamide test, $\mathrm{p}<0.05)$. After 24 weeks, group differences were still apparent on the ADAS-Cog $\left(\mathrm{F}_{2,42}=3.08, \mathrm{p}=0.06\right.$, $\mathrm{r}=0.36)$ and MMSE $\left(\mathrm{F}_{2,42}=8.48, \mathrm{p}=001, \mathrm{r}=0.54\right)$. Reanalyses showed that the experimental group was better than the ChEI control group on the ADAS-Cog $(\mathrm{p}<0.05)$, whereas the experimental and IPP control groups differed from the ChEIs control group on the MMSE $(p<0.05$; fig 2$)$. There was no significant change in SKT scores over 24 weeks across all three groups $\left(\mathrm{F}_{2,39}=0.83\right)$, and no significant group by time interaction $\left(\mathrm{F}_{2,39}=1.93, \mathrm{p}=0.11, \mathrm{r}=0.30\right)$.

Measures at week 12 and 24 are shown as compared with baseline (table 3).

No significant differences were observed in the functional assessments, as measured by the RDRS-2 at baseline examination (experimental group mean: 26.6 (SD 0.96), IPP control: 27.3 (0.93), ChEI control: $24.4(1.0) ; \mathrm{F}_{2,42}=2.16$, $\mathrm{p}=0.12, \mathrm{r}=0.32$ ), or after 24 weeks of follow-up (experimental group: 25.3 (1.1), IPP control: 25.6 (1.0), ChEI control: $\left.23.7(1.2) ; \mathrm{F}_{2,42}=0.76, \mathrm{p}=0.47, \mathrm{r}=0.14\right)$. The GDS stage was 4 in all patients at baseline and in all follow-up evaluations.

Figure 3 shows the mean difficulty level obtained by the patients over the course of the 24 weeks of treatment in each of the six cognitive domains of the IMIS. Performance in all cognitive domains showed an improvement, but most especially in the measures of attention and memory. In no case did a patient's performance level for any individual activity actually decline over the course of the 24 weeks.

\section{DISCUSSION}

This study shows that both classic cognitive stimulation treatment and computer-based treatment improved cognition in patients who were treated with a stable dose of ChEI, compared with those who were treated only with ChEIs. In addition, the IMIS program provided an improvement above and beyond that seen with classic cognitive stimulation, with improvement lasting 24 weeks. Not only did ADAS-Cog and MMSE scores fail to decline (as was seen in the ChEIs control group) but scores also actually improved, and the improvement was maintained over the 24 weeks that the IMIS was part of the treatment programme.

The progression of illness observed in the ChEI control group is consistent with what has previously been described in subjects with prolonged exposure to ChEIs ( $>1$ year).$^{38}$ On average, this group declined at a rate of approximately 2-3 MMSE points per year, which is slightly slower than is typical, but falls within the range of expected decline in mild Alzheimer's disease. ${ }^{39}$

These results show that it is possible to augment the effects of cholinesterase inhibition using cognitive stimulation procedures, with the result that patients have improved outcomes. These findings from the experimental group cannot be explained simply by increased social contact or interactions, as the experimental group and the IPP control group attended the daycare centre. The IMIS greatly augmented the traditional psychomotor stimulation, because when both treatments were used together efficacy was extended to 24 weeks. Thus, it seems that an individually constrained cognitive stimulation program such as the IMIS used here is more efficacious than treatment only with drugs, and at least augments traditional psychostimulation. In regard to the possible effects of IMIS-alone treatment, we hypothesise that it would represent an improvement compared with non-treated patients and also with patients treated with ChEIs alone, as shown in previous studies..$^{27} 40$

The degree of difficulty of the problems is individually adjusted to maximise success (and increase the challenges) for each patient. Although an understanding of the 
Table 2 Neuropsychological characteristics at baseline, and at 12 and 24 weeks follow-up examination

\begin{tabular}{|c|c|c|c|c|}
\hline Test & Assessment & Experimental group & IPP control group & ChEl control group \\
\hline \multirow{4}{*}{ MMSE } & Baseline & $20.60(2.10)$ & $22.50(2.90)$ & 22.83 (2.37) \\
\hline & Week 12 & $22.53(2.56)$ & $23.00(3.41)$ & $21.75(2.26)$ \\
\hline & Week 24 & $22.07(3.03)$ & $22.63(3.79)$ & $21.33(2.23)$ \\
\hline & Baseline & $22.40(5.70)$ & $21.19(5.73)$ & $20.00(4.35)$ \\
\hline \multirow[t]{3}{*}{ ADAS-cog } & Week 12 & $19.86(4.78)$ & $18.75(4.40)$ & $21.08(4.52)$ \\
\hline & Week 24 & $21.33(5.74)$ & $22.31(6.81)$ & $21.83(4.48)$ \\
\hline & Baseline & $11.80(3.88)$ & $11.62(4.91)$ & $13.83(5.72)$ \\
\hline \multirow[t]{3}{*}{ SKT } & Week 12 & $12.00(3.78)$ & $9.88(4.03)$ & $14.58(5.25)$ \\
\hline & Week 24 & $12.07(4.65)$ & $10.81(5.10)$ & $15.16(5.44)$ \\
\hline & Baseline & $36.53(10.64)$ & $36.31(7.04)$ & - \\
\hline \multirow[t]{3}{*}{ BNT } & Week 12 & 37.07 (10.05) & $38.63(7.04)$ & - \\
\hline & Week 24 & $37.20(10.26)$ & $37.25(8.21)$ & - \\
\hline & Baseline & $10.67(3.64)$ & $8.31(3.14)$ & - \\
\hline \multirow[t]{3}{*}{ Semantic fluency } & Week 12 & $10.93(3.04)$ & $9.13(3.63)$ & - \\
\hline & Week 24 & $9.60(4.41)$ & 8.75 (4.07) & - \\
\hline & Baseline & $9.53(3.93)$ & $8.19(3.54)$ & - \\
\hline \multirow[t]{2}{*}{ Phonetic fluency } & Week 12 & $9.00(3.98)$ & $7.94(3.89)$ & - \\
\hline & Week 24 & $9.20(3.53)$ & $8.19(4.09)$ & - \\
\hline \multirow{3}{*}{$\begin{array}{l}\text { Story recall subtest } \\
\text { (RBMT) }\end{array}$} & Baseline & $1.73(1.03)$ & $2.13(1.46)$ & - \\
\hline & Week 12 & $2.20(1.37)$ & $2.25(1.69)$ & - \\
\hline & Week 24 & $2.13(1.55)$ & $2.25(1.48)$ & - \\
\hline
\end{tabular}

ADAS-Cog, Alzheimer's Disease Assessment Scale-Cognitive; BNT, Boston Naming Test; ChEl, cholinesterase inhibitor; IPP, integrated psychostimulation program; MMSE, Mini-Mental State Examination; RBMT, Rivermead Behavioral Memory Test; SKT, Syndrom Kurztest.

physiological basis of the efficacy of these individualised cognitive stimulation programs is beyond the scope of this initial study, our findings and data from others suggest that plasticity remains possible in patients with Alzheimer's disease at the cellular level, and that these changes can modify disease progression. ${ }^{22-26}$ Cellular plasticity could thus provide a substrate on which the improvements observed here could be based.

No functional improvement was noted among the three groups. This may be explained by the fact that these were mildly impaired patients (mean MMSE was 22.0), who retained the physical or functional ability to participate in a cognitive or motor stimulation program, and did not exhibit disruptive behaviours. Similarly, the ChEI control group was only mildly impaired, and they had sufficient support from their care giver to come to the clinic for frequent evaluations. Therefore, any change in functional capacity could have been more difficult to measure in this cohort than in patients in moderate or severe stages of dementia. In addition, it is possible that the functional measures used in this study were not sensitive enough to detect subtle change.

There have been multiple methodological approaches to explore the benefits of non-pharmacological treatments in patients with Alzheimer's disease. These included studies of:

- memory training in one specific task (eg, errorless learning paradigm) and its effects on memory function, ${ }^{41}{ }^{42}$ or on

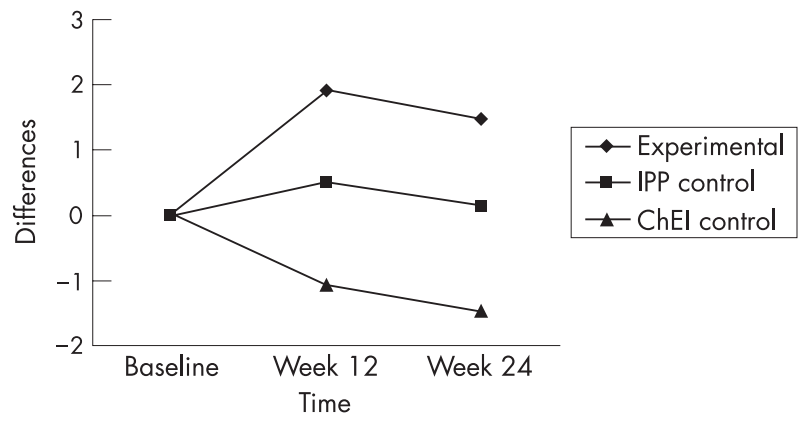

Figure 1 Mini-Mental State Examination mean change at 12 and 24 weeks. ChEl, cholinesterase inhibitor; IPP, integrated psychostimulation program. other cognitive functions ${ }^{43}$ or activities of daily living $(\mathrm{ADLs})^{44}$;

- training in ADLs (procedural memory stimulation) and its effects on the same tasks ${ }^{45}$;

- psychosocial intervention programmes (ie, reality orientation treatment $)^{46}$;

- combination of cognitive stimulation and counselling (patients and care givers) ${ }^{47}$;

- combination of cognitive rehabilitation with mental stimulation techniques ${ }^{48}$;

- combination of cognitive enhancers and computerised cognitive training ${ }^{49}$; and

- comprehensive cognitive and motor stimulation programmes. ${ }^{16}$

Although these approaches show varying degree of benefits from non-pharmacological interventions in patients with Alzheimer's disease, it is difficult to establish comparisons among studies, as the outcome measures and duration of the interventions were not the same, especially when compared with drug trials. Studies of non-pharmacological interventions should, therefore, use the same outcome measures and study duration as the pharmacological trials to provide a better perspective of the effects of non-pharmacological treatments. This study used the ADAS-Cog and MMSE, which are the standard cognitive measures used in drug trials; participants who had cognitive or motor stimulation

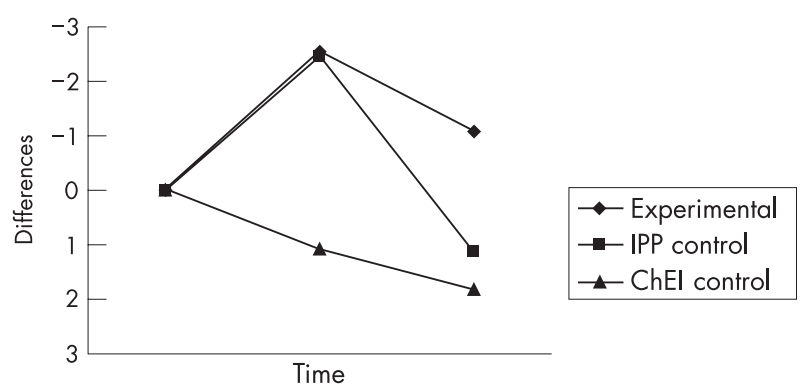

Figure 2 Alzheimer's Disease Assessment Scale-Cognitive mean change after 12 and 24 weeks. ChEI, cholinesterase inhibitor; IPP, integrated psychostimulation program. 
Table 3 Mean change in cognitive measures at 12 and 24 weeks follow-up

\begin{tabular}{|c|c|c|c|c|}
\hline Test & Assessment & Experimental group & IPP control group & ChEl control group \\
\hline & Baseline & 0 & 0 & 0 \\
\hline \multirow[t]{3}{*}{ MMSE } & Week 12 & 1.93 & 0.50 & -1.08 \\
\hline & Week 24 & 1.47 & 0.13 & -1.50 \\
\hline & Baseline & 0 & 0 & 0 \\
\hline \multirow[t]{3}{*}{ ADAS-Cog ${ }^{*}$} & Week 12 & -2.54 & -2.44 & 1.08 \\
\hline & Week 24 & -1.07 & 1.12 & 1.83 \\
\hline & Baseline & 0 & 0 & 0 \\
\hline \multirow[t]{3}{*}{$\mathrm{SKT}^{*}$} & Week 12 & 0.20 & -1.74 & 0.75 \\
\hline & Week 24 & 0.27 & -0.81 & 1.33 \\
\hline & Baseline & 0 & 0 & - \\
\hline \multirow[t]{3}{*}{ BNT } & Week 12 & 0.54 & 2.32 & - \\
\hline & Week 24 & 0.67 & 0.94 & - \\
\hline & Baseline & 0 & 0 & - \\
\hline \multirow[t]{3}{*}{ Semantic fluency } & Week 12 & 0.26 & 0.82 & - \\
\hline & Week 24 & -1.07 & 0.44 & - \\
\hline & Baseline & 0 & 0 & - \\
\hline \multirow[t]{3}{*}{ Phonetic fluency } & Week 12 & 0.53 & -0.25 & - \\
\hline & Week 24 & 0.33 & 0 & - \\
\hline & Baseline & 0 & 0 & - \\
\hline \multirow[t]{2}{*}{ Story recall subtest (RBMT) } & Week 12 & 0.47 & 0.12 & - \\
\hline & Week 24 & 0.40 & 0.12 & - \\
\hline
\end{tabular}

treatment had improved scores, and this effect was enhanced by the use of a computerised program.

One of the limitations of the study is that we were unable to complete the neuropsychological battery (secondary outcomes) in the ChEI control group. Therefore, we could not further expand our analysis to specific cognitive domains. The improvement seen with the ADAS-Cog and the MMSE was not seen with the SKT. This discrepancy could be explained by assessing whether these treatments have beneficial effects in some cognitive domains, and not in others. However, the limited scope of the cognitive functions assessed by the SKT, and a possible ceiling effect in mildly impaired patients can also explain these findings.

The patients in the experimental and the IPP control groups were in the daycare centre; the only difference between the groups was that the experimental group received the IMIS. Patients in these groups were drawn from the same institution, where the IPP program is used in all patients. Therefore, we could not create a group of patients receiving daycare only, as patients could not be isolated from their daily stimulation routines (which are an integral part of the daycare program).

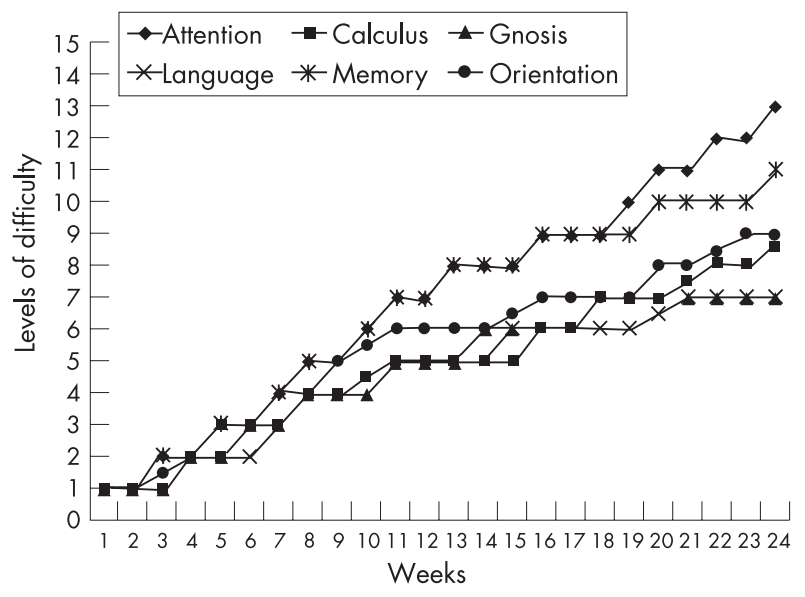

Figure 3 Mean levels of difficulty attained by the experimental group on each cognitive function over a 24 -week training period.
Although this was a trial of a non-pharmacological intervention, one way to conceptualise the design is to consider that we were able to evaluate "dose" and "tolerability". In this context, the "dose" refers to the amount of time each day that a patient could engage in the IMIS. Similarly, we could consider the patient's willingness to complete the assigned tests on schedule as a measure of "tolerability". Therefore, we started with sessions of $15 \mathrm{~min}$ of duration and increased them to $25 \mathrm{~min}$, and all patients completed the minimum requirement of 58 sessions.

Future research is needed to evaluate the efficacy of the IMIS-type programs in larger, more diverse populations to understand factors that may modify the response, as well as to establish its long-term effects ( $>1$ year). The IMIS should be tested outside the controlled clinical environment (ie, home-based) to determine the efficacy of "distance therapy" in Alzheimer's disease. Nevertheless, the results of this study suggest that this is a promising avenue of approach to help maximise a patient's cognitive functions in the context of a progressive degenerative disease, potentially altering the effect of the condition on both the patients and the care givers.

\section{ACKNOWLEDGEMENT}

This study was conducted with an unrestricted grant from Fundació ACE, Institut Català de Neurociències Aplicades, Barcelona, Spain.

\section{Authors' affiliations}

L Tárraga, M Boada, G Modinos, A Espinosa, S Diego, A Morera,

M Guitart, J Balcells, Fundació ACE. Institut Català de Neurociències Aplicades, Barcelona, Spain

O L López, J T Becker, Departments of Neurology and Psychiatry, University of Pittsburgh School of Medicine, Pittsburgh, Pennsylvania, USA

Competing interests: None declared.

\section{REFERENCES}

1 Ott A, Breteler MM, van Karskamp F, et al. Incidence and risk of dementia. The Rotterdam Study. Am J Epidemiol 1998;147:574-80.

2 Fratiglioni L, Launer $\amalg, K A$, Breteler MM, et al. Incidence of dementia and major subtypes in Europe: a collaborative study of population-based cohorts. Neurology 2000;54:S10-S15.

3 Rogers SL, Friedhoff LT. The efficacy and safety of donepezil in patients with Alzheimer's disease: results of a US multicentre, randomized, double-blind, 
placebo-controlled trial. The Donepezil Study Group. Dementia 1996;7:293-303.

4 Rosler $M$, Anand R, Cicin-Sain A, et al. Efficacy and safety of rivastigmine in patients with Alzheimer's disease: international randomised controlled trial. BMJ 1999:318:633-8.

5 Raskind MA, Peskind ER, Wessel T, et al. Galantamine in AD. A six-month, randomized, placebo-controlled trial with a six-month extension. Neurology 2000;54:2261-8.

6 Tariot PN, Farlow MR, Grossberg GT, et al. Memantine treatment in patients with moderate to severe Alzheimer's disease already receiving donepezil. JAMA 2004;291:317-24.

7 Breuil V, DeRetrou J, Forette F. Cognitive stimulation of patients with dementia: preliminary results. Int J Geriatr Psychiatry 1994;9:21 1-17.

8 Woods RT. Non-pharmacological techniques. In: Qizilbash N, Schneider LS, Chui $\mathrm{H}$, et al, eds. Evidence-based dementia practice. Oxford: Blackwell, 2002:428-46.

9 Douglas S, James I, Ballard C. Non-pharmacological interventions in dementia. Adv Psychiatr Treat 2004:10:171-9.

10 Grandmaison E, Simard M. A critical review of memory stimulation programs in Alzheimer's disease. J Neuropsychiatr Clin Neurosci 2003;15:130-44.

11 Clare L, Woods RT, Moniz-Cook ED, et al. Cognitive rehabilitation and cognitive training for early-stage Alzheimer's disease and vascular dementia [Review]. Cochrane Database Syst Rev 2003:4:CD003260.

12 Katzman R. Education and the prevalence of dementia and Alzheimer's disease. Neurology 1993;43:13-20.

13 Verghese J, Lipton RB, Katz MJ, et al. Leisure activities and the risk of dementia in the elderly. N Engl J Med 2003;348:2508-16.

14 Wilson RS, Mendes de León CF, Barnes LL. Participation in cognitively stimulating activities and risk of incident Alzheimer's disease. JAMA 2002;287:742-8.

15 Stern Y, Alexander GE, Prohovnik I, et al. Relationship between lifetime occupation and parietal flow: implications for a reserve against Alzheimer's disease pathology. Neurology 1995;44:55-60.

16 Olazarán J, Muñiz R, Reisberg B, et al. Benefits of cognitive-motor intervention in $\mathrm{MCl}$ and mild to moderate Alzheimer disease. Neurology 2004;63:2348-53.

17 Tárraga L. Soft therapies: the programme of integral psychostimulation. Alternative treatment for persons with Alzheimer's disease. Rev Neurol 1998;27(Suppl 1):S51-S62.

18 Jankowsky JL, Melnikova T, Fadale DJ, et al. Environmental enrichment mitigates cognitive deficits in a mouse model of Alzheimer's disease. $J$ Neurosci 2005:25:5217-24.

19 Arendash GW, García MF, Costa DA, et al. Environmental enrichmen improves cognition in aged Alzheimer's transgenic mice despite stable betaamyloid deposition. NeuroReport 2004;15:1751-4.

20 Berchtold NC, Chinn G, Chou M, et al. Exercise primes a molecular memory for brain-derived neurotrophic factor protein indiction in the rat hippocampus. Neuroscience 2005;133:853-61.

21 Adlard PA, Perreau VM, Pop V, et al. Voluntary exercise decreases amyloid load in a transgenic model of Alzheimer's disease. J Neurosci 2005:25:4217-21.

22 Kemperman G, Gast D, Gage FH. Neuroplasticity in old age: sustained fivefold induction of hippocampal neurogenesis by long-term environmental enrichment. Ann Neurol 2002;52:135-43.

23 Fernández-Ballesteros $\mathrm{R}$, Zamarrón MD, Tárraga L. Learning potential: a new method for assessing cognitive impairment. Int Psychogeriatr 2005; 17:119-28.

24 Becker JT, Mintun MA, Aleva K, et al. Compensatory reallocation of brain resources supporting verbal episodic memory in Alzheimer's disease. Neurology 1996;46:692-700.

25 Herbster AN, Nichols T, Wiseman MB, et al. Functional connectivity in auditory verbal short-term memory in Alzheimer's disease. Neuroimage 1996;4:67-77

26 Dekosky ST, Scheff SW. Synapse loss in frontal cortex biopsies in Alzheimer's disease: correlation with cognitive severity. Ann Neurol 1990;27:457-64.
27 Hofmann M, Hock C, Kuhler A, et al. Interactive computer-based cognitive training in patients with Alzheimer's disease. J Psychiatr Res 1996;30:493-501

28 McKhann G, Drachman DA, Folstein MF, et al. Clinical diagnosis of Alzheimer's disease: report of the NINCDS-ADRDA Work Group under the auspices of the Department of Health and Human Services Task Force on Alzheimer's disease. Neurology 1984;34:939-44.

29 Folstein MF, Folstein SE, McHugh PR. Mini-mental state: a practical method grading the cognitive state of patients for the clinician. Psychiatr Res 1975; 12:189-98.

30 Blesa R, Pujol M, Aguilar M. Clinical validity of the "mini-mental state" for Spanish speaking communities. Neuropyschologia 2001;39:1150-7.

31 Reisberg B, Gordon B, McCarthy M, et al. Clinical symptoms accompanying progressive cognitive decline and Alzheimer's disease. In: Melnick VL, Dubler NN, eds. Alzheimer's dementia. Clifton, NJ: Humana Press, 1985:19-39.

32 American Psychiatric Association. DSM-IV: Diagnostic and Statistic Manual of Mental Disorders, 4th edn. Washington, DC: American Psychiatric Association, 1994.

33 Rosen WG, Mohs RC, Davis KL. A new rating scale for Alzheimer's disease. Am J Psychiatry 1984;141:1356-64.

34 Erzigkeit $\mathrm{H}$. The SKT: a short cognitive performance test as an instrument for the assessment of clinical efficacy of cognitive enhancers. In: Berenger $M$, Reisberg B, eds. Diagnosis and treatment of senile dementia. Berlin: Springer Verlag, 1989: 164-74.

35 Goodglass H, Kaplan E, Weintraub S. In: The assessment of aphasia and related disorders, 2nd edn. Philadelphia: Lea and Febiger, 1987.

36 Wilson B, Cockburn J, Baddeley A. The Rivermead Behavioral Memory Test. Reading: Thames Valley Test Company, 1985.

37 Linn MW, Linn BS. The rapid disability rating scale, part 2. J Am Geriatr Soc 1982;139:1136-9.

38 Doody RS, Geldmacher DS, Gordon B, et al. Open-label, multicenter, phase 3 extension study of the safety and efficacy of donepezil in patients with Alzheimer disease. Arch Neurol 2001;58:427-33.

39 Doody RS, Dunn JK, Clark CM, et al. Chronic donepezil treatment is associated with slowed cognitive decline in Alzheimer's disease. Dement Geriatr Cogn Disord 2001;12:295-300.

40 Hofmann M, Rosler A, Schwarz W, et al. Interactive computer-training as a therapeutic tool in Alzheimer's disease. Compr Psychiatry 2003;44:213-19.

41 Clare L, Wilson BA, Roth I, et al. Relearning face-name associations in early Alzheimer's disease. Neuropsychology 2002;16:538-47.

42 Clare L, Wilson BA, Carter G, et al. Cognitive rehabilitation as a component of early intervention in Alzheimer's disease: a single case study. Aging Ment Health 2003;7:5-6.

43 Davis RN, Massman PJ, Doody RS. Cognitive intervention in Alzheimer disease: a randomized placebo-controlled study. Alzheimer Dis Assoc Disord 2001; 15:1-9.

44 Cahn-Weiner DA, Malloy PF, Rebok GW, et al. Results of a randomized placebo-controlled study of memory training for mildly impaired Alzheimer's disease patients. Appl Neuropsychol 2003;10:215-23.

45 Zanetti O, Binetti G, Magni E, et al. Procedural memory stimulation in Alzheimer's disease: impact of training programme. Acta Neurol Scand 1997; $95: 152-7$

46 Metitieri T, Zanetti O, Geroldi C, et al. Reality orientation therapy to delay outcomes of progression in patients with dementia. A retrospective study. Clin Rehab 2001;15:471-8.

47 Quayhagen MP, Quayhagen M, Corbeil RR, et al. Coping with dementia: evaluation of four nonpharmacologic interventions. Int Psychogeriatr 2000; 12:249-65

48 Loewenstein DA, Acevedo A, Czaja SJ, et al. Cognitive rehabilitation of mildly impaired Alzheimer disease patients on cholinesterase inhibitors. Am J Geriatr Psychiatr 2004;12:395-402.

49 Heiss W-D, Kessler J, Mielke R, et al. Long-term effects of phosphatidylserine, pyritinol and cognitive training in Alzheimer's disease. A neuropsychological, EEG, and PET investigation. Dementia 1994;5:88-98. 